\title{
Unsymmetrical Single-Component Nickel 1,2-Dithiolene Complexes with Extended Tetrachalcogenafulvalenedithiolato Ligands
}

\author{
George C. Anyfantis ${ }^{\mathrm{a}}$, George C. Papavassiliou ${ }^{\mathrm{a}}$, Panagiotis Aloukos ${ }^{\mathrm{b}}$, Stelios Couris ${ }^{\mathrm{b}}$, \\ Yufeng F. Weng ${ }^{\mathrm{c}}$, Harukazu Yoshino ${ }^{\mathrm{c}}$, and Keizo Murata ${ }^{\mathrm{c}}$ \\ a Theoretical and Physical Chemistry Institute, National Hellenic Research Foundation, \\ 48, Vassileos Constantinou Ave., Athens 116-35, Greece \\ $\mathrm{b}$ Institute of Chemical Engineering and High Temperature Chemical Processes (ICE-HT), \\ Foundation for Research and Technology-Hellas (FORTH), Patras 265-04, Greece and \\ Department of Physics, University of Patras, Patras 265-04, Greece \\ ${ }^{c}$ Graduate School of Science, Osaka City University, Sumiyoshi-ku, Osaka 558-8585, Japan \\ Reprint requests to Prof. G. C. Papavassiliou. Fax (30210)7273794. E-mail: pseria@eie.gr
}

Z. Naturforsch. 2007, 62b, 200-204; received September 21, 2006

The unsymmetrical complexes $\mathrm{Ni}(\mathrm{dmdt})(\mathrm{dmio})$ and $\mathrm{Ni}(\mathrm{dmstfdt})(\mathrm{dmio})(\mathrm{dmdt}=$ dimethyltetrathiafulvalenedithiolate, $\mathrm{dmstfdt}=$ dimethyldiselenadithiafulvalenedithiolate, dmio $=1,3$-dithiol-2-one4,5-dithiolate) were prepared and characterized analytically and spectroscopically. The complexes exhibit strong third-order nonlinear optical response in the visible and near-infrared spectral regions.

Key words: Metal 1,2-Dithiolenes, Nonlinear Optics, Organic Semiconductors

\section{Introduction}

In our previous papers, the preparation and characterization of some neutral metal 1,2-dichalcogenolene complexes have been reported [1-5]. Crystal structure determinations of two of them showed strong intermolecular interactions, due to $\mathrm{S} \cdots \mathrm{S}$ and/or $\mathrm{S} \cdots \mathrm{Se}$ contacts $[3 \mathrm{a}, 4]$. Their r.t. conductivity values were found to be in the range $10^{-9}-10^{-5} \mathrm{~S} \mathrm{~cm}^{-1}[3,4]$. Also, the complexes exhibited strong optical absorption (OA) bands in the near infrared (near IR) spectral region. Some unsymmetrical complexes with a "push-pull" (donor-acceptor) character were found to exhibit enhanced nonlinear optical (NLO) properties in solution [5] (see also [6]). In some unsymmetrical complexes, the distribution of electrons in the $\left(\mathrm{C}_{2} \mathrm{~S}_{2}\right)_{2} \mathrm{Ni}$ core and the terminal groups is estimated and related with the NLO properties (see [6a] and refs. therein). Very recently, the electrical properties of some neutral symmetrical and unsymmetrical complexes such as $\mathrm{Ni}(\mathrm{dpedt})_{2}$ and $\mathrm{Ni}($ pddt)(dmio) have been reported (where dpedt is diphenyl-ethylenedithiolate, pddt is 6,7-dihydro-5H-1,4-dithiepin-2,3dithiolate, and dmio is 1,3-dithiol-2-one-4,5-dithiolate) $[3,4 a, 7]$. These compounds exhibit semiconducting behaviour under conditions of field-effect transistors (FETs) [3b, 4, 7-9].
In this paper, the preparation and characterization of the unsymmetrical complexes $\mathrm{Ni}(\mathrm{dmdt})(\mathrm{dmio})$ and $\mathrm{Ni}(\mathrm{dmstfdt}$ )(dmio) (where dmdt is dimethyltetrathiafulvalenedithiolate and dmstfdt is dimethyldiselenadithiafulvalenedithiolate) are described. The complexes were prepared by the cross-coupling type method [2-4], according to the procedure outlined in Scheme 1 . The starting materials $(\mathbf{1}-\mathbf{3})$ were prepared by methods reported in $[10-13]$. The required unsymmetrical complexes were separated from the corresponding symmetrical byproducts by column chromatography and characterized analytically and spectroscopically. In this particular kind of unsymmetrical complexes one ligand is a $\pi$-donor (extended tetrachalcogenafulvalenedithiolate) [13] and the other one is a $\pi$-acceptor (dmio) $[6,11]$. From a number of unsymmetrical complexes with an extended tetrachalcogenafulvalenedithiolato ligand, which we have designed and prepared [3-5], these two complexes were found to be most interesting for further investigation.

\section{Results and Discussion}

From equimolar amounts of compounds $\mathbf{1}$ and $\mathbf{2}$, the complex $\mathrm{Ni}(\mathrm{dmdt})(\mathrm{dmio})$ was obtained in $3 \%$ yield while the complex $\mathrm{Ni}(\mathrm{dmstfdt})(\mathrm{dmio})$ was obtained 


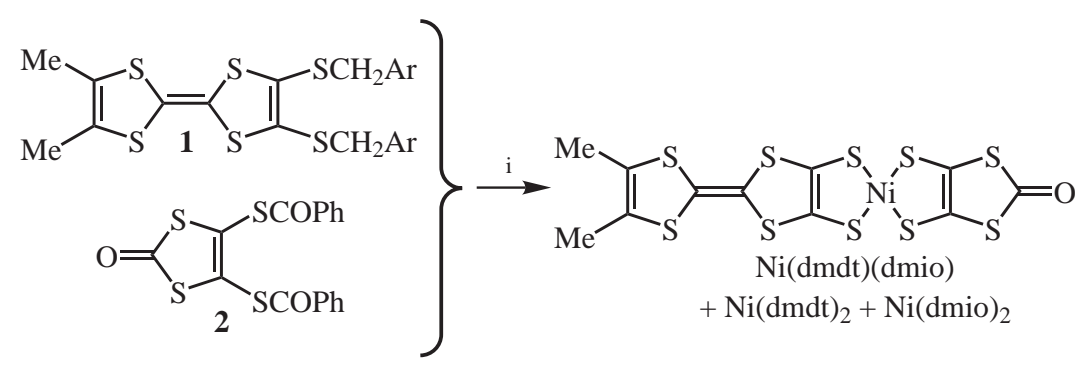

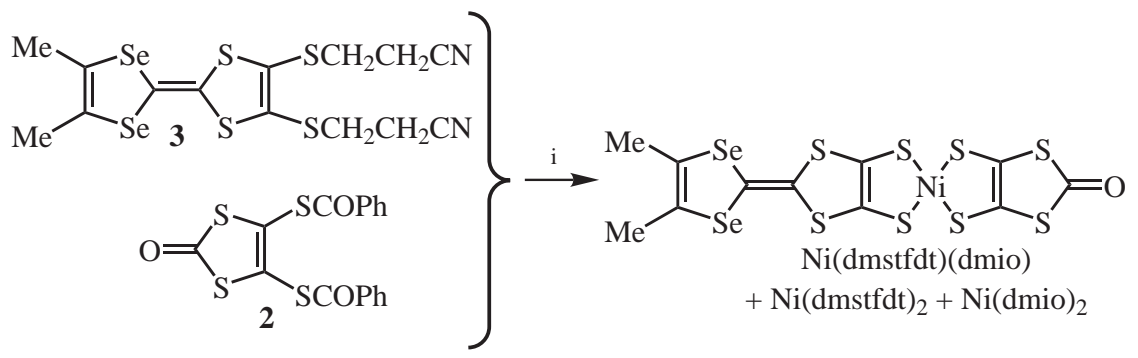

$\mathrm{i}=1) \mathrm{NaOMe}, 2) \mathrm{NiCl}_{2}$ in $\left.\mathrm{MeOH}, 3\right)$ aqu. $\mathrm{HCl}$, in air; $\mathrm{Ar}=p-\mathrm{AcOC}_{6} \mathrm{H}_{4^{-}}$

Scheme 1.

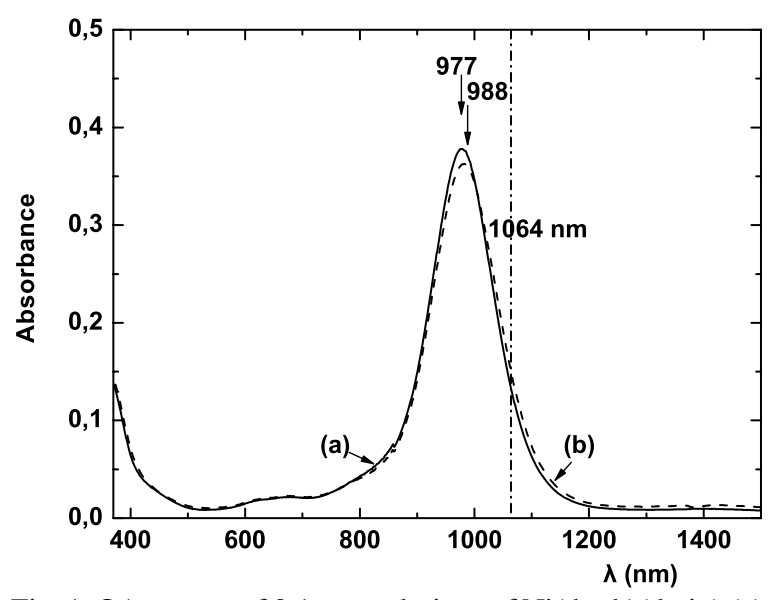

Fig. 1. OA spectra of $0.1 \mathrm{~mm}$ solutions of $\mathrm{Ni}(\mathrm{dmdt})(\mathrm{dmio})(\mathrm{a})$ and $\mathrm{Ni}(\mathrm{dmstfdt})(\mathrm{dmio})(\mathrm{b})$ in $\mathrm{CS}_{2}$.

from equimolar amounts of $\mathbf{2}$ and $\mathbf{3}$ in $7 \%$ yield. Both complexes are soluble in $\mathrm{CS}_{2}$ and in some other organic solvents. The corresponding symmetrical complexes $\mathrm{Ni}(\mathrm{dmdt})_{2}$ and $\mathrm{Ni}(\mathrm{dmstfdt})_{2}[11,13]$ are not soluble in organic solvents. Moreover, the complex $\mathrm{Ni}(\mathrm{dmio})_{2}$ cannot be isolated in a pure form, but instead a cation-deficient product can be obtained, which also is not soluble in organic solvents [11]. The unsymmetrical complexes were found to be stable in air, as it is expected from the redox behaviour of the corresponding symmetrical ones $[2,11,13]$. From solutions of $\mathrm{Ni}(\mathrm{dmdt})(\mathrm{dmio})$ and $\mathrm{Ni}(\mathrm{dmstfdt})(\mathrm{dmio})$ thin needles of the complexes were obtained. These needles were not suitable for successful single crystal X-ray diffraction experiments, however. Conductivity measurements on compressed pellets of the complexes showed weak semiconducting behaviour, arising from the intermolecular interactions as in the cases of similar complexes [3,4]. By application of the cross-coupling method of Scheme 1 (see also [2,5]), it is possible to obtain complexes stable in air and soluble in organic solvents. Also, it is possible to tune the position of the optical absorption band to the desired wavelength [6]. This is a way to create the optimum trade-off between the near resonance and the low optical absorption coefficient, as required for NLO devices [6b]. In the present cases, the optical absorption (OA) spectra of solutions of $\mathrm{Ni}(\mathrm{dmdt})(\mathrm{dmio})$ and $\mathrm{Ni}(\mathrm{dmstfdt})(\mathrm{dmio})$ in $\mathrm{CS}_{2} \mathrm{ex}-$ hibit the low-energy bands at 977 and $988 \mathrm{~nm}$, respectively (see Fig. 1). These bands arise from the low-energy $\pi-\pi^{*}$ transitions (see [6] and references therein). The OA spectrum of $\mathrm{Ni}(\mathrm{dmdt})(\mathrm{dmio})$ as a thin deposit on a quartz plate is shown in Fig. 2a. The spectrum exhibits a broad low-energy band at $c a .1270 \mathrm{~nm}$, i.e., at shorter wavelength than that of the symmetrical complex $\mathrm{Ni}(\mathrm{dmdt})_{2}$, but almost at the same wavelength as that of $\operatorname{Pd}(\mathrm{dt})_{2}$ (where dt is tetrathiafulvalenedithiolate), which is a semiconducting material insoluble in organic solvents [13]. This band is shifted towards shorter wavelengths ( $c a .1130 \mathrm{~nm})$ after grinding the deposit (Fig. 2b). Similar results were ob- 
Table 1. Nonlinear optical parameters of complexes at 532 and $1064 \mathrm{~nm}$.

\begin{tabular}{|c|c|c|c|c|c|c|c|}
\hline \multirow[b]{2}{*}{ Dithiolene complex } & \multicolumn{3}{|c|}{$532 \mathrm{~nm}$} & \multicolumn{4}{|c|}{$1064 \mathrm{~nm}$} \\
\hline & $\begin{array}{c}\alpha_{0}^{*} \\
\left(\mathrm{~cm}^{-1}\right)\end{array}$ & $\begin{array}{c}\operatorname{Re} \chi^{(3)} \\
\left(\times 10^{-13} \mathrm{esu}\right)\end{array}$ & $\begin{array}{c}\gamma \\
\left(\times 10^{-29} \text { esu }\right)\end{array}$ & $\begin{array}{c}\alpha_{0}{ }^{*} \\
\left(\mathrm{~cm}^{-1}\right)\end{array}$ & $\begin{array}{c}\operatorname{Re} \chi^{(3) *} \\
\left(\times 10^{-13} \mathrm{esu}\right)\end{array}$ & $\begin{array}{c}\operatorname{Im} \chi^{(3) *} \\
\left(\times 10^{-13} \mathrm{esu}\right)\end{array}$ & $\underset{\left(\times 10^{-29} \mathrm{esu}\right)}{\gamma}$ \\
\hline$\overline{\mathrm{Ni}(\mathrm{dmdt})(\mathrm{dmio})}$ & 0.192 & -80 & $2.3 \pm 0.2$ & 3.1 & -3100 & -760 & $92 \pm 5$ \\
\hline $\mathrm{Ni}(\mathrm{dmstfdt})(\mathrm{dmio})$ & 0.23 & -129 & $3.7 \pm 0.8$ & 3.5 & -3400 & -1356 & $106 \pm 5$ \\
\hline
\end{tabular}

${ }^{*} \alpha_{0}$ is the linear absorption, corresponding to a concentration of $0.1 \mathrm{mmol}$.

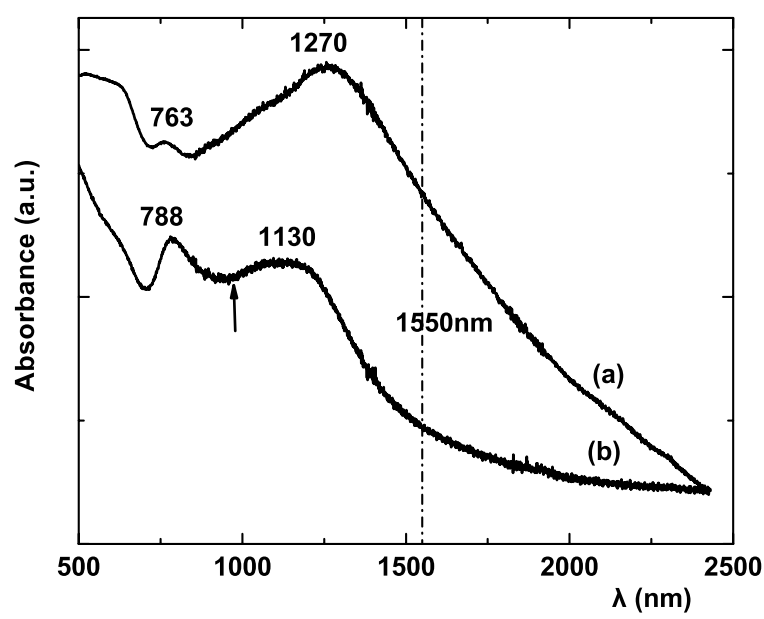

Fig. 2. OA spectra of thin deposits of $\mathrm{Ni}(\mathrm{dmdt})(\mathrm{dmio})$ before (a) and after (b) grinding on a quartz plate. The arrow indicates the OA band-position of a solution in $\mathrm{CS}_{2}$.

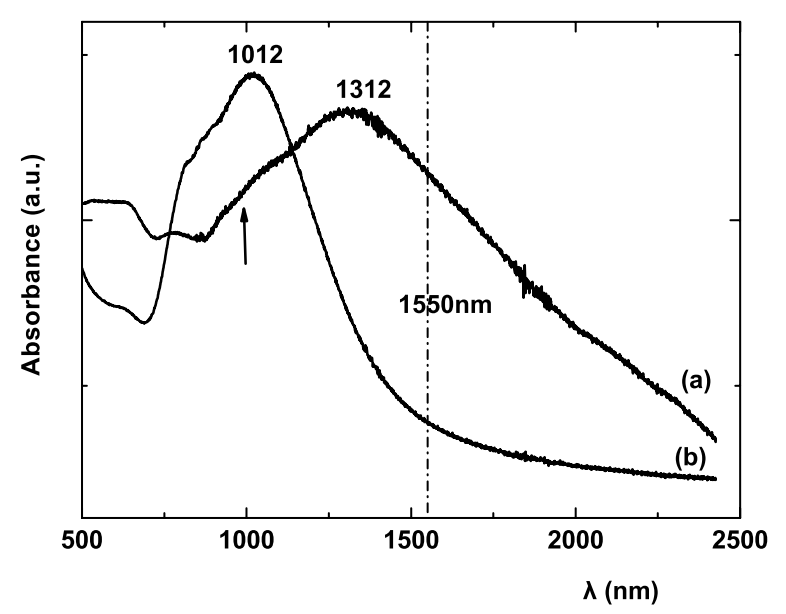

Fig. 3. OA spectra of thin deposits of Ni(dmstfdt)(dmio) before (a) and after (b) grinding on a quartz plate. The arrow indicates the OA band-position of a solution in $\mathrm{CS}_{2}$.

tained from thin deposits of $\mathrm{Ni}(\mathrm{dmtsfdt})(\mathrm{dmio})$, with $\mathrm{OA}$ bands at 1312 and $1010 \mathrm{~nm}$ before and after grinding, respectively (Fig. 3). The OA bands of the grinded deposits of both complexes occur close to those of solutions in $\mathrm{CS}_{2}$, but are broader. The shift of the OA bands to shorter wavelengths after grinding is attributed to the decrease of the intermolecular interactions. Similar effects have been observed in other synthetic materials with semiconducting behaviour [14]. In the similar complexes $\mathrm{Ni}(\mathrm{dmdt})(\mathrm{dmit})$ and $\mathrm{Ni}(\mathrm{dmtsfdt})(\mathrm{dmit})$ (where dmit is 1,3-dithiol-2thione-4,5-dithiolate [11c]), obtained by the same method but in very low yields, the OA bands occur at longer wavelengths than those of $\mathrm{Ni}(\mathrm{dmdt})(\mathrm{dmio})$ and $\mathrm{Ni}(\mathrm{dmtsfdt})(\mathrm{dmio})$. In another unsymmetrical complex, Ni(eodt)(dmit) (where eodt is ethylenedioxytetrathiafulvalenedithiolate $[12,13])$, the OA bands occur at shorter wavelengths. The results indicate that the complexes $\mathrm{Ni}(\mathrm{dmdt})(\mathrm{dmio})$ and $\mathrm{Ni}(\mathrm{dmtsfdt})(\mathrm{dmio})$ are suitable to obtain near resonance and low absorption for the near IR lasers (Figs. 1-3).

Important transient NLO response of solutions of the complexes in $\mathrm{CS}_{2}$ was observed at 532 and $1064 \mathrm{~nm}$ using $8 \mathrm{~ns}$ pulses. Table 1 presents the determined values of the third-order susceptibility $\chi^{(3)}$ and the second hyperpolarizability $\gamma$. As seen in Table 1, hyperpolarizability values at $1064 \mathrm{~nm}$ are significantly larger than those at $532 \mathrm{~nm}$, reflecting the strong resonant enhancement taking place at this wavelength. A similar behaviour has been observed by the authors of ref. [5] for some other unsymmetrical dithiolene complexes.

The complexes $\mathrm{Ni}(\mathrm{dmdt})(\mathrm{dmio})$ and $\mathrm{Ni}(\mathrm{dmtsfdt})$ (dmio) with donor (dmdt or dmstfdt) and acceptor (dmio) moieties could be candidates for second-order NLO properties as it has been shown for some other unsymmetrical complexes with donor-acceptor moieties $[6 \mathrm{a}, 6 \mathrm{c}]$. Also, it is expected that these unsymmetrical complexes and similar ones with extended tetrachalcogenafulvalenedithiolato ligands will exhibit NLO properties in the solid state (thin deposits on several substrates, or dispersions in polymer matrices) with lasers operating at 1064 or longer wavelengths (e.g., 1300 and $1550 \mathrm{~nm}$ ), considering that the typical wavelength for optical communication is $1550 \mathrm{~nm}$ $(0.8 \mathrm{eV})$ (see [15] and references therein). However, some structural and spectroscopic data as well as theo- 
retical calculations are required for the electronic distribution (metal-ligand) and the correlation with the NLOP [6a]. Finally, this kind of unsymmetrical complexes as well as the previously reported ones [2$4,17]$, which are weak semiconductors, could be candidate materials of FETs [3,4,7-9] and/or photoconductors $[17,18]$ for various applications [3-8, $15-18]$.

\section{Experimental Section}

(Dimethyltetrathiafulvalenedithiolato)(1,3-dithiol-2-one4,5-dithiolato)nickel, $\mathrm{Ni}(\mathrm{dmdt})(\mathrm{dmio})$

In a two-necked $250 \mathrm{~mL}$ flask, a solution of $\mathrm{NaOMe}$, freshly prepared from $\mathrm{Na}(80.5 \mathrm{mg}, 3.5 \mathrm{mmol})$ and deoxygenated $\mathrm{MeOH}(30 \mathrm{~mL})$, was added to a suspension of compound 1 ( $296 \mathrm{mg}, 0.5 \mathrm{mmol}$ ) in deoxygenated $\mathrm{MeOH}$ $(5 \mathrm{~mL})$, under nitrogen atmosphere, and the mixture was stirred for $1 \mathrm{~h}$. Compound 2 (195 mg, $0.5 \mathrm{mmol}$ ) was added and the stirring was continued for $15 \mathrm{~min}$. To the obtained red-brown solution, a solution of $\mathrm{NiCl}_{2} \cdot 6 \mathrm{H}_{2} \mathrm{O}(120 \mathrm{mg}$, $0.5 \mathrm{mmol})$ in deoxygenated $\mathrm{MeOH}(25 \mathrm{~mL})$ was added dropwise within $20 \mathrm{~min}$. The solution turned brown and was stirred under nitrogen atmosphere for $1 \mathrm{~h}$ at r.t. Then, aq. $\mathrm{HCl}(1 \mathrm{~mL}, 35 \%)$ was added and the mixture was transferred to a beaker and stirred in air overnight. The precipitate was washed with water and $\mathrm{MeOH}$ and dried in air. The greenbrown solid was extracted with $\mathrm{CS}_{2}$ and chromatographed on silica gel, using $\mathrm{CS}_{2}$ as eluent. The first green fraction contained $\mathrm{Ni}(\mathrm{dmdt})(\mathrm{dmio})(8 \mathrm{mg}, 3 \%)$. M.p. $246{ }^{\circ} \mathrm{C}$ (dec.). - UV/vis/near IR $\left(\mathrm{CS}_{2}\right): \lambda_{\max }\left(\lg \varepsilon_{\max }\right)=977 \mathrm{~nm}(4.58)$. - IR (KBr): $v=1621,1665(\mathrm{C}=\mathrm{O}), 2923\left(\mathrm{CH}_{3}\right) \mathrm{cm}^{-1}$. $-\mathrm{C}_{11} \mathrm{H}_{6} \mathrm{OS}_{10} \mathrm{Ni}$ (533.5): calcd. C 24.76, H 1.12; found C 24.80, H 1.17.

\section{(Dimethyldiselenadithiafulvalenedithiolato)(1,3-dithiol-2- one-4,5-dithiolato)nickel, Ni(dmstfdt)(dmio)}

In a two-necked $250 \mathrm{~mL}$ flask, a solution of $\mathrm{NaOMe}$, freshly prepared from $\mathrm{Na}(72.5 \mathrm{mg}, 3.15 \mathrm{mmol})$ and deoxygenated $\mathrm{MeOH}(30 \mathrm{~mL})$, was added to a suspension of compound 3 (225 mg, $0.45 \mathrm{mmol}$ ) in deoxygenated $\mathrm{MeOH}$ $(5 \mathrm{~mL})$, under nitrogen atmosphere, and the mixture was stirred for $2 \mathrm{~h}$. Compound 2 (175.5 mg, $0.45 \mathrm{mmol}$ ) was added and the stirring was continued for $15 \mathrm{~min}$. To the obtained red-brown solution, a solution of $\mathrm{NiCl}_{2} \cdot 6 \mathrm{H}_{2} \mathrm{O}$ (107.6 mg, $0.45 \mathrm{mmol})$ in deoxygenated $\mathrm{MeOH}(25 \mathrm{~mL})$ was added dropwise within $20 \mathrm{~min}$. The solution turned brown and was stirred under nitrogen atmosphere for $1 \mathrm{~h}$ at $\mathrm{r}$.t. Then, aq. $\mathrm{HCl}(1 \mathrm{~mL}, 35 \%)$ was added and the mixture was transferred to a beaker and stirred in air overnight. The precipitate was washed with water and $\mathrm{MeOH}$ and dried in air. The green-brown solid was extracted with $\mathrm{CS}_{2}$ and chromatographed on silica gel, using $\mathrm{CS}_{2}$ as eluent. The first green fraction contained $\mathrm{Ni}(\mathrm{dmstfdt})(\mathrm{dmio})(20 \mathrm{mg}, 7 \%)$. M. p. $255^{\circ} \mathrm{C}$ (dec.). $-\mathrm{UV} /$ vis/near IR $\left(\mathrm{CS}_{2}\right): \lambda_{\max }\left(\lg \varepsilon_{\max }\right)=$ $988 \mathrm{~nm}$ (4.56). - IR (KBr): $v=1625,1657(\mathrm{C}=\mathrm{O}), 2922$ $\left(\mathrm{CH}_{3}\right) \mathrm{cm}^{-1}$. - $\mathrm{C}_{11} \mathrm{H}_{6} \mathrm{OS}_{8} \mathrm{Se}_{2} \mathrm{Ni}$ (627.28): calcd. C 21.06, $\mathrm{H}$ 0.96; found C 21.13, H 1.08 .

\section{Instrumentation}

All measurements were performed at r.t. Resistivity measurements were performed on compressed polycrystalline pellets by the well known voltage-drive method. Thin deposits of the complexes on quartz plates were obtained by spraying or spinning $\mathrm{CS}_{2}$ solutions of the complexes. Very dilute deposits were obtained by grinding the original deposits between two quartz plates. The optical absorption spectra of solutions or several deposits in the UV/vis/near IR spectral region were recorded on a Perkin Elmer, model Lambda 19 spectrophotometer. The NLO measurements were performed by the standard $Z$-scan technique, using a Q-switched $8 \mathrm{~ns} \mathrm{Nd}$ :YAG laser of $10 \mathrm{~Hz}$ operating at 532 and $1064 \mathrm{~nm}[5,16]$.

\section{Acknowledgements}

The work was carried out as a part of the "Excellence in the Research Institutes" project grant 0684, supported by GSRT/Ministry of Development in Greece. S.C. and P.A. acknowledge partial support from EU though the "NANOPHOS" project grant IST-2001-39112.
[1] G. C. Papavassiliou, G. A. Mousdis, G. C. Anyfantis, Z. Naturforsch. 2002, 57b, $707-708$.

[2] G. C. Papavassiliou, G. C. Anyfantis, Z. Naturforsch. 2005, $60 b, 811-813$.

[3] a) G.C. Anyfantis, G.C. Papavassiliou, A. Terzis, C. P. Raptopoulou, Y. F. Weng, H. Yoshino, K. Murata, Z. Naturforsch. 2006, 61b, $1007-1011$; b) Th. D. Antho- poulos, G.C. Anyfantis, G.C. Papavassiliou, unpublished work the concerning ambipolar transistors from $\mathrm{Ni}$ (dpedt)(dmit) (where dmit is 1,3-dithiol2-thione-4,5-dithiolate).
[4] a) G. C. Papavassiliou, G. C. Anyfantis, B. R. Steele, A. Terzis, C. P. Raptopoulou, G. Tatakis, G. Chaidogiannos, N. Glezos, Y. F. Weng, H. Yoshino, K. Murata, Single-Component Metal 1,2-Dithiolene Complexes as Candidate Semiconductors for Field-Effect Transistors. Abstracts in Proc. of Int. Conf. Synth. Metals, Dublin 2006, No 023 TU; b) G. C. Anyfantis, G. C. Papavassiliou, C. P. Raptopoulou, A. Terzis, unpuplished work concerning the crystal structure of Ni(dmeds)(dmit) (where dmeds is dimethylethylenediselenolate and dmit is 1,3-dithiol-2-thione-4,5-dithiolate). 
[5] P. Aloukos, S. Couris, J. B. Koutselas, G. C. Anyfantis, G.C. Papavassiliou, Chem. Phys. Lett. 2006, $428,109-113$; second hyperpolarizability instead of second-order hyperpolarizability should be corrected therein.

[6] a) S. Curreli, P. Deplano, C. Faulmann, A. Ienco, C. Mealli, M. L. Mercuri, L. Pilia, G. Pintus, A. Serpe, E. F. Trogu, Inorg. Chem. 2004, 43，5069-5079; b) Z. Dai, X. Yue, B. Peng, Q. Yang, X. Liu, P. Ye, Chem. Phys. Lett. 2000, 317, 9-12; c) C. Yang, J. Qin, Q. Yang, J. Si, S. Wang, Y. Wang, P. Ye, C. Ye, Synth. Met. 2001, 121, $1491-1492$.

[7] a) T. Taguchi, H. Wada, T. Kambayashi, B. Noda, M. Goto, T. Mori, K. Ishikawa, H. Takezoe, Chem. Phys. Lett. 2006, 421, $395-398$; b) E.C.P. Smits, Th. D. Anthopoulos, S. Setayesh, E. van Veenendaal, R. Coehoorn, P.W. M. Blom, B. de Boer, D. M. de Leeuw, Phys. Rev. B 2006, 73, 205316 1-9.

[8] Y. Sun, Y. Liu, D. Zhu, J. Mater. Chem. 2005, 15, $53-$ 65.

[9] C. Pearson, A. J. Moore, J.E. Gibson, M. R. Bryce, M. C. Petty, Thin Solid Films 1994, 244, 932-935.

[10] a) C. Gemmell, J. D. Kildurn, H. Ueck, A. E. Underhill, Tetrahedron Lett. 1992, 33, 3923 - 3926; b)Y. Misaki, T. Matsui, K. Kawakami, H. Nishikawa, T. Yamada, M. Shiro, Chem. Lett. 1993, 22, 1337-1340.

[11] a) S. Ikegawa, K. Miyawaki, T. Nogami, Y. Shirota, Bull. Chem. Soc. Jpn. 1993, 66, 2770 - 2772; b) Sh.-G. Liu, Y.-Q. Liu, D. B. Zhu, Synth. Met. 1996, 79, 49 56; c) G. Steimecke, H.-J. Sieler, R. Kirmse, E. Hoyer, Phosphorus and Sulfur. 1979, 7, 49-55.
[12] L. Binet, J. M. Fabre, C. Montginoul, K. B. Simonsen, J. Becher, J. Chem. Soc., Perkin Trans. 1 1996, $783-$ 788.

[13] a) A. Kobayashi, E. Fujiwara, H. Kobayashi, Chem. Rev. 2004, 104, 5243 - 5264; b) A. Kobayashi, M. Sasa, W. Suzuki, E. Fujiwara, H. Tanaka, M. Tokumoto, Y. Okano, H. Fujiwara, H. Kobayashi, J. Am. Chem. Soc. 2004, 126, 426-427.

[14] G. C. Papavassiliou, Prog. Sol. St. Chem. 1997, 25, $125-270$.

[15] a) H. Kishida, H. Matsuzaki, H. Okamoto, T. Manabe, M. Yamashita, Y. Taguchi, Y. Tokura, Nature 2000, 405, 929 -932; b) C. Faulmann, P. Gassoux, Prog. Inorg. Chem. 2004, 52, 399-489.

[16] M. Sheik-Bahae, A. A. Said, T.-H. Wei, D. J. Hagan, E. W. van Styland, IEEE J. Quantum Electron. 1990, $26,760-769$.

[17] M. Aragoni, M. Arca, F. A. Devillanova, F. Isaia, V. Lippolis, A. Mancini, L. Pala, A. M. Z. Slawin, J. D. Woollins, Inorg. Chem. 2005, 44, 9610-9612.

[18] a) M.C. Aragoni, M. Arca, T. Cassano, C. Denotti, F. A. Devillanova, F. Isaia, V. Lippolis, D. Natali, L. Nitti, M. Sampietro, R. Tommasi, G. Verani, Inorg. Chem. Commun. 2002, 5, 869-872; b) M. C. Aragoni, M. Arca, M. Caironi, C. Denotti, F. A. Devillanova, F. Grigiotti, F. Isaia, F. Laschi, V. Lippolis, D. Natali, L. Pala, M. Sampietro, P. Zanello, Chem. Commun. 2004, $1882-1883$. 